\title{
Glutamate signaling in healthy and diseased bone
}

\author{
Robert W. Cowan, Eric P. Seidlitz and Gurmit Singh* \\ Department of Pathology and Molecular Medicine, McMaster University, Hamilton, ON, Canada
}

\section{Edited by:}

Deborah Mason, Cardiff University,

UK

\section{Reviewed by:}

Roger Brooks, University of

Cambridge, UK

Chantal Chenu, Royal Veterinary

College, UK

*Correspondence:

Gurmit Singh, Juravinski Cancer

Centre, Room 4-225, 699 Concession

Street, Hamilton, ON, Canada

L8V 5 C2.

e-mail: gurmit.singh@jcc.hhsc.ca
Bone relies on multiple extracellular signaling systems to maintain homeostasis of its normal structure and functions. The amino acid glutamate is a fundamental extracellular messenger molecule in many tissues, and is used in bone for both neural and non-neural signaling. This review focuses on the non-neural interactions, and examines the evolutionarily ancient glutamate signaling system in the context of its application to normal bone functioning and discusses recent findings on the role of glutamate signaling as they pertain to maintaining healthy bone structure. The underlying mechanisms of glutamate signaling and the many roles glutamate plays in modulating bone physiology are featured, including those involved in osteoclast and osteoblast differentiation and mature cell functions. Moreover, the relevance of glutamate signaling systems in diseases that affect bone, such as cancer and rheumatoid arthritis, is discussed, and will highlight how the glutamate system may be exploited as a viable therapeutic target. We will identify novel areas of research where knowledge of glutamate communication mechanisms may aid in our understanding of the complex nature of bone homeostasis. By uncovering the contributions of glutamate in maintaining healthy bone, the reader will discover how this complex molecular signaling system may advance our capacity to treat bone pathologies.

Keywords: glutamate, bone, rheumatoid arthritis, signaling, bone disease, cancer, homeostasis, pathology
Glutamate (in the form of L-glutamate) is a non-essential amino acid that is the most common excitatory neurotransmitter in the central nervous system (CNS; Bleich et al., 2003). Glutamate signaling is phylogenetically ancient and common in both plants and animals (Chiu et al., 1999), likely evolving from an important role in the regulation of carbon and nitrogen metabolism (Davenport, 2002). Synthesized intracellularly in mammalian cells, glutamate is primarily formed from glutamine using the enzyme glutaminase, to produce an ammonium ion useful for excess nitrogen disposal (Young and Ajami, 2001). Transamination of $\alpha$-ketoglutarate, an intermediate of the citric acid cycle, also generates glutamate (Waddell and Miller, 1991). Glutamate is widely used as an intercellular communication molecule (see reviews by Watkins and Jane, 2006; Krnjevic, 2010), and although characterized more fully in the CNS, all of the essential components for glutamate signaling have been identified in non-neural systems (Skerry and Genever, 2001; Nedergaard et al., 2002; Hinoi et al., 2004a). Moreover, a fully functional glutamate signaling system is present in bone (Spencer et al., 2007). Although numerous systemic, local, and neural factors are involved in regulating bone remodeling (Berenson et al., 2006; Elefteriou, 2008; Martin and Seeman, 2008), there is growing recognition of the importance of glutamate signaling in bone homeostasis (Nedergaard et al., 2002; Hinoi et al., 2004b; Spencer et al., 2004). Following an overview of the structural components of glutamate signaling systems, this review will evaluate how these structures are involved in maintaining bone homeostasis with a particular emphasis on their potential involvement in a variety of bone diseases. Indeed, several disease states may be potentiated by a disruption of normal glutamatergic signaling. A better understanding of glutamate intercellular communication in healthy and diseased bone will aid in determining whether these signaling components may represent viable therapeutic targets in bone disease.

\section{GLUTAMATE SIGNALING STRUCTURES}

In neurons, glutamate signaling involves several distinct steps - signal release via vesicular transporters, reception by specific receptors, and termination of the signal using uptake transporters. Each of these steps must work in concert to function effectively, and imbalances can lead to failure of the system (Olney, 1969). Figure 1 summarizes, on a generic cell, the different classes of glutamate transporters and receptors that can be involved in glutamate signaling.

There are two main categories of glutamate transporters - the predominantly vesicular glutamate export transporters which are sodium-independent, and the non-vesicular plasma membrane glutamate import transporters which are sodium-dependent. There are four types of vesicular export transporters - namely VGLUT-1 to VGLUT-3 (Hayashi et al., 2003; Tremolizzo et al., 2006; Liguz-Lecznar and Skangiel-Kramska, 2007) and sialin, a recently characterized vesicular glutamate/aspartate transporter (Miyaji et al., 2010). Although non-vesicular, the system $\mathrm{x}_{\mathrm{c}}^{-}$glutamate/cystine antiporter is a membrane-bound glutamate exporter, and exchanges intracellular glutamate for extracellular cystine (Bannai, 1986). This amino acid exchange accumulates cystine to synthesize the antioxidant glutathione (Kim et al., 2001). For glutamate import, the excitatory amino acid transporters (EAATs) are critically important for the termination of glutamate - a good review of their properties has been prepared by Tzingounis and Wadiche (2007). There are five known non-vesicular reuptake 


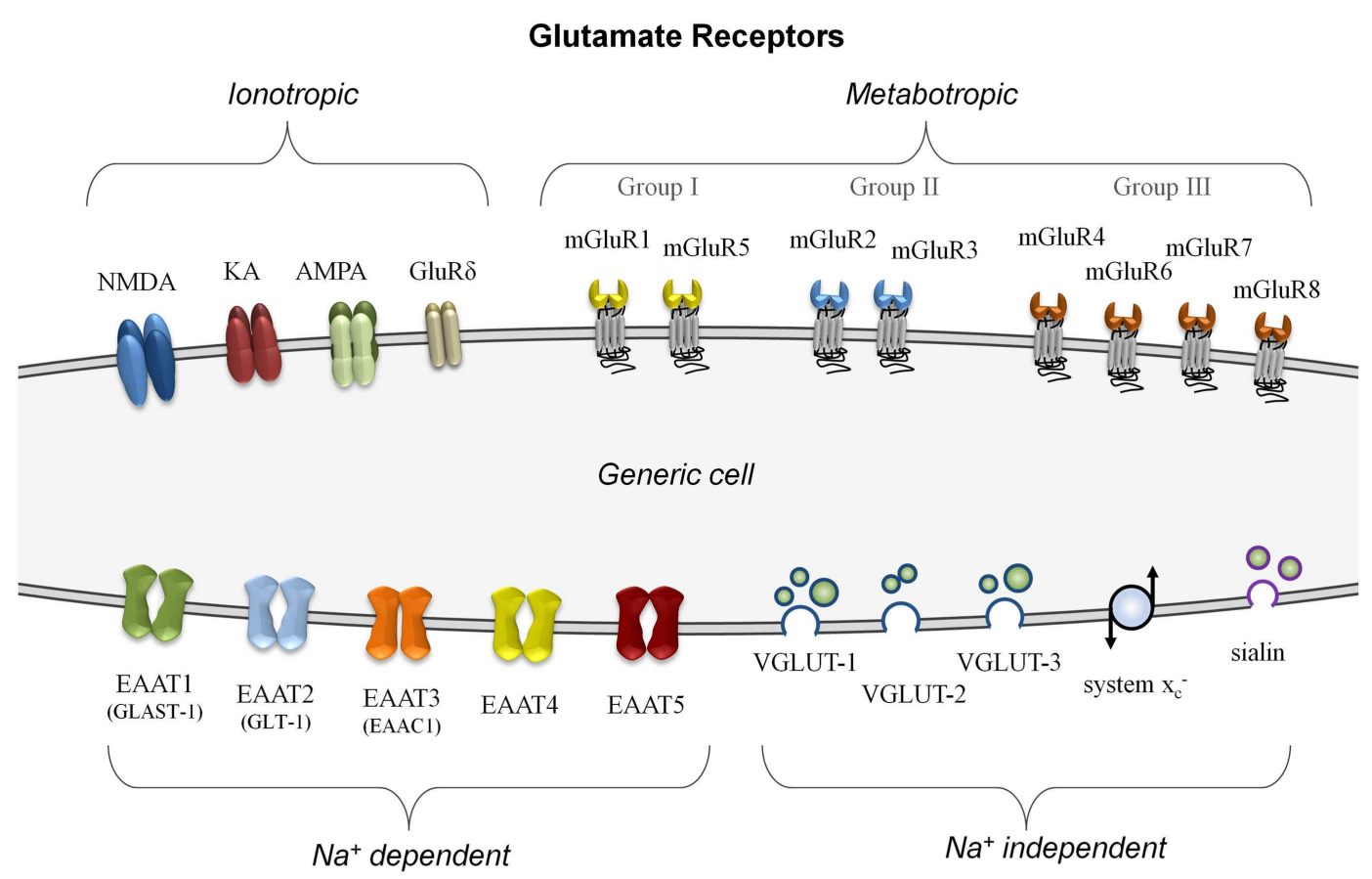

Glutamate Transporters

FIGURE 1 |A summary of known glutamate receptor and transporter structures. For simplification, these structures are depicted on a generic model cell, although no cell is known to express all of these components simultaneously. Glutamate receptors are divided into either ionotropic or metabotropic types. Ionotropic receptors can incorporate different combinations of functional subunits, conferring varying response properties, and allowing for co-agonist activation. The metabotropic receptors, subdivided into three groups, are G-protein coupled membrane receptors that do not form ion channels although they can modulate other glutamate signaling components. Glutamate transporters are divided into those that are sodium-dependent and those that do not require a sodium gradient for their activity. The plasma membrane transporters (EAAT1 to EAAT5) can form ion channels and most often import glutamate. The sodium-independent transporters primarily export glutamate and these include the vesicular transporters (VGLUT-1 to VGLUT-3 and sialin) and the non-vesicular system $x_{c}^{-}$ glutamate/cystine antiporter. transporters, named EAAT1 to EAAT5 (Shigeri et al., 2004). The neuronal EAAT1 transporter is also called the glutamate-aspartate transporter (GLAST-1; Huggett et al., 2002) due to its ability to transport both amino acids, while the human EAAT2 transporter known as glutamate transporter-1 (GLT-1) is often expressed in glial cells and pre-synaptic neurons (Mason et al., 1997). Although both GLAST-1 and GLT-1 primarily function as importers of glutamate, they are also capable of glutamate export under strong potassium gradients (Marcaggi et al., 2005).

One of the advantages of using glutamate for signaling is the incredible diversity of responses that can result from this molecule. Response flexibility is accomplished by an array of glutamate receptor types that can generate different responses depending on how they are expressed. Glutamate receptors are divided into two major groups on the basis of their mode of action - ionotropic glutamate receptors (iGluRs), which form iongated cation channels when activated, and metabotropic glutamate receptors (mGluRs), which are coupled to intracellular G-proteins and regulate the production of intracellular second messengers. An excellent review by Dingledine et al. (1999) provides a comprehensive overview of glutamate receptors and their functions, primarily within the CNS. Briefly, there are three main groups of iGluRs named according to their synthetic agonist specificity:
$\mathrm{N}$-methyl-D-aspartate (NMDA) receptors, $\alpha$-amino-3-hydroxy-5methyl-4-isoxazolepropionic acid (AMPA) receptors, and kainate (KA) receptors. Although not widely known, a fourth family of iGluRs termed the delta receptors exists, with two subtypes identified (GluR $\delta 1$ and GluR $\delta 2$ ), although they may only be secondarily involved in glutamate signaling (Kakegawa et al., 2011; Tanahashi et al., 2012). The iGluRs are comprised of tetramers of different subunits in various combinations that form ion channels with distinct properties. There are eight different mGluRs (mGluR1 to mGluR8) that are divided into three groups based on sequence homology and their signal transduction pathways (Niswender and Conn, 2010). Providing both excitatory and inhibitory responses, the mGluRs often modulate other systems via their second messenger activation and complex interactions with other proteins (Enz, 2007).

\section{GLUTAMATE SIGNALING IN HEALTHY BONE}

Considerable evidence exists to suggest that glutamate signaling in normal bone is involved in a variety of processes, including cell differentiation effects and mature cell functions. Glutamate concentrations within the bone environment are modulated by a variety of cell types, through glutamate-specific transporters which are expressed by the bone-resorbing osteoclasts (Oc; Hinoi 
et al., 2007), bone-building osteoblasts (Ob; Takarada-Iemata et al., 2011; Uno et al., 2011), osteocytes (Huggett et al., 2002), and chondrocytes (Wang et al., 2006). In fact, virtually all cell types in normal bone have the ability to secrete glutamate to some extent through multiple mechanisms. The amount of glutamate available for release may be controlled through enzymatic processes. For example, glucocorticoids and Wnt signaling may inversely regulate glutamine synthetase activity in osteoblasts (Olkku et al., 2004; Olkku and Mahonen, 2008), which catalyzes the conversion of glutamate to glutamine.

A variety of glutamate receptors and subunit combinations are expressed within the bone environment, enabling a very high degree of control over the cellular responses to glutamate signals. The most well-characterized glutamate receptors in normal bone are the NMDA-type receptors, with confirmed expression in Oc, Ob, osteocytes, and bone marrow mononuclear cells (Chenu et al., 1998; Patton et al., 1998; Genever et al., 1999; Itzstein et al., 2001). Inhibition of these receptors prevents early differentiation of both Ob (Hinoi et al., 2003; Lin et al., 2008) and Oc (Peet et al., 1999; Merle et al., 2003; Lin et al., 2008) into their functionally active cell types. However, an inhibitor of system $\mathrm{x}_{\mathrm{c}}^{-}$, which reduces glutamate release without acting on the receptors, was also able to inhibit Oc differentiation (Suematsu et al., 2007). This implies that glutamate released by other cells within the bone may signal for the generation of new Oc or Ob via NMDA receptors. Moreover, glutamate has been shown to suppress $\mathrm{Ob}$ cell proliferation at the very earliest stages of differentiation from their mesenchymal stem cell progenitors, which express multiple types of glutamate receptors and transporters themselves (Iemata et al., 2007). Other receptor types are also expressed by normal bone cells, including metabotropic (Gu and Publicover, 2000; Hinoi et al., 2001; Szczesniak et al., 2005; Kalariti et al., 2007) and non-NMDA ionotropic receptors such as KA and AMPA receptors (Chenu et al., 1998; Hinoi et al., 2002; Taylor, 2002; Szczesniak et al., 2005). Table 1 summarizes the glutamate receptors and transporters expressed by normal bone cells. Deletion of osteoblastic NMDA receptor expression as well as targeted administration of iGluR antagonists were reported to impede skeletal development in mouse models (Skerry, 2008). Indeed, the AMPA receptors may also participate in $\mathrm{Ob}$ differentiation, as stimulation of this receptor increases mineral deposition and osteocalcin expression (Lin et al., 2008).

Glutamatergic signaling components are also involved in the adult functions of bone cells. In particular, Oc transport bone degradation products from the bone surface in vesicular structures and remove them from the apical end of the cell in a process called transcytosis (Yamaki et al., 2005). This essential transportation function interacts directly with VGLUT-1, which adds glutamate to the transcytotic vesicles containing the bone degradation products and upon release by the Oc, glutamate acts in an autocrine manner to suppress further bone resorption, likely through mGluR8 (Morimoto et al., 2006). However, regulation of bone resorption is also impaired by inhibitors of ionotropic receptors (Chenu et al., 1998; Peet et al., 1999; Itzstein et al., 2000), further demonstrating the complexity of this regulatory system.

To prevent continued signaling between bone cells, extracellular glutamate concentrations are reduced by plasma membrane transporters. The most studied transporter in this regard is GLAST-1, and it is constitutively expressed by $\mathrm{Ob}$ and osteocytes (Mason et al., 1997; Huggett et al., 2002; Mason and Huggett, 2002; Kalariti et al., 2007; Spencer et al., 2007), but not by Oc. However, Ob and osteocytes are not the only cells capable of sequestering free glutamate, as GLT-1 is also expressed by Oc, chondrocytes, and mononuclear bone marrow cells (Mason et al., 1997; Hinoi et al., 2005b, 2007; Spencer et al., 2007). Moreover, EAAT3 and EAAT4 are also expressed by $\mathrm{Ob}$ (Takarada et al., 2004) and Oc (Hinoi et al., 2007), respectively.

\section{GLUTAMATE SIGNALING IN DISEASED BONE}

Owing to their participation in normal bone cell functioning, disruption of the glutamatergic signaling mechanisms may lead to various disease pathologies. For example, use of a specific group II/III mGluR antagonist stimulates in vitro bone resorption by Oc compared to untreated controls (Morimoto et al., 2006). This effect is thought to result from inhibition of mGluR8, which in turn may prevent glutamate from participating in the negative feedback cascade produced by transcytosis, thereby resulting in continued Oc resorption. As mentioned, intracellular glutamate is added to the transcytotic vesicles by VGLUT-1 as part of this Oc activity feedback mechanism, and correspondingly, VGLUT-1 knockout mice develop osteoporosis due to increased bone resorption (Morimoto et al., 2006). Moreover, differential expression of NMDA receptor subunits in chondrocytes may promote osteoarthritis (Ramage et al., 2008), and glutamate signaling via NMDA receptors on osteoarthritic chondrocytes can mediate inflammatory responses (Piepoli et al., 2009).

Notably, bone homeostasis may be indirectly disrupted by glutamatergic signaling in non-bone cells as well. For example, NMDA receptors present within the parathyroid glands or kidneys may contribute to altered secretion of parathyroid hormone (Parisi et al., 2009, 2010), which can lead to both bone resorption and bone formation. Moreover, glutamate potently stimulates secretion of the hormone leptin from white adipocytes (Cammisotto et al., 2005), which, in turn, can inhibit bone formation by signaling through the sympathetic nervous system (Ducy et al., 2000; Takeda et al., 2002). Additionally, glutamate itself may affect neuronal control of bone mass, as monosodium glutamate-sensitive neurons can stimulate bone formation (Elefteriou et al., 2003).

\section{CANCER}

Cancers are perhaps the most significant disease to result in disruption of glutamatergic signaling. Indeed, glutamate is an established contributor to the pathophysiology of gliomas (see de Groot and Sontheimer, 2011 for a recent review). However, glutamatergic signaling components are also present in multiple cancers (Stepulak et al., 2009; Sharma et al., 2010), signifying the fundamental importance of glutamate in many biologic systems. Glutamate itself may also directly participate in cancer initiation, as melanocytes from transgenic mice induced to express mGluR5 subsequently developed into melanomas (Choi et al., 2011).

With respect to bone, numerous cancers that metastasize to bone were demonstrated to express several glutamate receptors and transporters, and these included breast, prostate, and lung cancers (Rzeski et al., 2001; Narang et al., 2003; Doxsee et al., 2007; Sharma et al., 2010). Limited information is available on 
Table 1 | A summary of glutamate signaling components expressed by normal bone cells.

\begin{tabular}{|c|c|c|c|c|c|c|c|}
\hline & & & Osteoclast & Osteoblast & Osteocyte & Marrow cells & Chondrocyte \\
\hline \multicolumn{8}{|c|}{ GLUTAMATE RECEPTORS } \\
\hline \multirow{3}{*}{\multicolumn{2}{|c|}{ Ionotropic }} & NMDA & + & + & + & + & + \\
\hline & & AMPA & + & + & \pm & \pm & + \\
\hline & & GluR $\delta$ & & & & & \\
\hline & $\|$ & mGluR2 & & \pm & & + & \\
\hline & & mGluR3 & + & + & & & \\
\hline & III & mGluR4 & + & \pm & & + & \\
\hline & & mGluR6 & + & \pm & & & \\
\hline & & mGluR7 & + & \pm & & + & \\
\hline & & EAAT3 (EAAC1) & - & + & & & + \\
\hline & & EAAT4 & + & \pm & & & \\
\hline & & EAAT5 & - & - & & & \\
\hline \multirow[t]{5}{*}{$\mathrm{Na}^{+}$independent } & & VGLUT-1 & + & + & & & \\
\hline & & VGLUT-2 & - & - & & & \\
\hline & & VGLUT-3 & - & - & & & \\
\hline & & System $x_{c}^{-}$ & + & + & & & + \\
\hline & & Sialin & & & & & \\
\hline
\end{tabular}

This table summarizes published reports of protein and/or RNA expression of glutamate receptors and transporters and demonstrates how they are differentially expressed in primary or cultured bone cells. Most cell types in the bone (potentially all) express the structures to release, receive, and terminate glutamate signals through multiple mechanisms (+, expressed; -, not expressed; \pm , inconclusive; blank, unknown/not evaluated).

the participation of glutamate signaling in primary bone cancers, although human osteosarcoma cell lines express several glutamate receptors (Genever and Skerry, 2001; Itzstein et al., 2001; Kalariti et al., 2004, 2007) and GLAST-1 (Kalariti et al., 2004, 2007). NMDA receptor subunits were also identified in Oc-like giant cells from giant cell tumor of bone (Itzstein et al., 2001). Glutamate is likely important for proper tumor cell functioning, as inhibition of glutamate receptors can limit cell growth in many cancer cell lines (Rzeski et al., 2001). Conversely, pharmacologic prevention of glutamate release in osteosarcoma cells results in an inhibition of differentiation and increased apoptosis (Genever and Skerry, 2001). Therefore glutamate signaling in general may represent an important target for bone metastasis and primary tumor treatments, particularly since bone is uniquely sensitive to altered extracellular glutamate (Seidlitz et al., 2010a).

As an excitatory amino acid, glutamate may also contribute to nociception resulting from bone cancers. Indeed, in a mouse model, sarcoma cells injected into the medullary cavity of the distal femur stimulated behavioral changes indicative of bone cancer pain and increased the expression of mGluR3 and mGluR5 in the spinal cord (Ren et al., 2012). Stimulation of mGluR3 or inhibition of mGluR5 in the CNS reduced bone cancer pain, suggesting differential expression of these receptors in the spinal cord may amplify nociceptive signaling (Ren et al., 2012). Moreover, a similar model demonstrated increased expression of the NMDA receptor subunit NR2B in the spinal cord, and inhibition of NMDA receptor activity decreased pain symptoms (Gu et al., 2010). However, glutamate from non-neural sources may also stimulate nociceptors in bone, and cancer cells release significant amounts of glutamate via the system $\mathrm{x}_{\mathrm{c}}^{-}$glutamate/cystine antiporter (Seidlitz et al., 2009; Sharma et al., 2010). This transporter is an especially attractive therapeutic target in cancer as inhibiting its functions can increase sensitivity of the cancer cell to oxidative stress. An excellent review by Lo et al. (2008) discusses system $\mathrm{x}_{\mathrm{c}}^{-}$inhibition and its potential to limit tumor growth and sensitize cancers to other treatments largely through pharmacologic inhibition of cystine intake, which leads to inadequate glutathione production and an increased sensitivity to oxidative stress. Excess glutamate may further disrupt the bone by interfering with the normally balanced Oc and Ob intercellular signaling, as a moderate increase in extracellular glutamate was able to increase mineralized bone formation in cultured $\mathrm{Ob}$ (Seidlitz et al., 2010b). In this respect, therapeutic inhibition of system $\mathrm{x}_{\mathrm{c}}^{-}$in the cancer cells may relieve bone pain symptoms by reducing their glutamate secretion while simultaneously preventing tumor growth, reducing bone disruption, and sensitizing the tumor to radiation or chemotherapeutic agents.

\section{RHEUMATOID ARTHRITIS}

Glutamate signaling is also relevant in rheumatoid arthritis (RA). For example, glutamate concentrations in synovial fluid were reported to increase more than 50-fold in patients with RA compared to controls, from 6.25 to $326 \mu \mathrm{M}$ (McNearney et al., 
2000) and both glutamate receptors and transporters are expressed by synovial fibroblasts (Hinoi et al., 2005a; Flood et al., 2007). RA, a chronic disorder characterized by synovial inflammation, can result in degradation of cartilage and bone by the invading pannus. As with cancer, excess glutamate within the synovial fluid may correspond with increased nociception (Sluka et al., 1994; Lawand et al., 1997). Glutamate signaling is also thought to contribute to the inflammatory response, as a KA receptor antagonist decreases expression of interleukin-6 in primary synovial fibroblasts (Flood et al., 2007), and exogenous glutamate was found to stimulate tumor necrosis factor- $\alpha$ expression in primary synovial cell cultures established from RA patients (McNearney et al., 2004). NMDA receptor antagonists also increase expression of pro-matrix metalloproteinase 2 in RA synovial fibroblasts (Flood et al., 2007). Moreover, blood glutamate concentration is associated with increased bone resorption in RA patients (Hajati et al., 2009, 2010). Not surprisingly, therefore, modulation of glutamate signaling may alleviate RA symptoms. It is intriguing to note that a common treatment for RA is sulfasalazine, and this drug is particularly effective at inhibiting the system $\mathrm{x}_{\mathrm{c}}^{-}$glutamate/cystine antiporter (Doxsee et al., 2007). Indeed, the importance of glutamate in arthritis is further highlighted using rodent arthritis models, as inhibition of NMDA with memantine delayed the onset of collagen-induced arthritis and reduced bone resorption in mice (Lindblad et al., 2012). The use of non-NMDA ionotropic receptor antagonists (Sluka et al., 1994), or a combination of NMDA and non-NMDA ionotropic receptor antagonists (Lam and Ng, 2010) also reduced swelling and alleviated pain symptoms in rat early arthritis models.

\section{CONCLUSION}

Healthy bone is maintained in an exquisitely balanced state by numerous intercellular communication systems. Evidence that glutamate signaling is a significant participant in bone homeostasis

\section{REFERENCES}

Bannai, S. (1986). Exchange of cystine and glutamate across plasma membrane of human fibroblasts. J. Biol. Chem. 261, 2256-2263.

Berenson, J. R., Rajdev, L., and Broder, M. (2006). Pathophysiology of bone metastases. Cancer Biol. Ther. 5, 1078-1081.

Bleich, S., Romer, K., Wiltfang, J., and Kornhuber, J. (2003). Glutamate and the glutamate receptor system: a target for drug action. Int. J. Geriatr. Psychiatry 18(Suppl. 1), S33-S40.

Cammisotto, P. G., Gelinas, Y., Deshaies, Y., and Bukowiecki, L. J. (2005). Regulation of leptin secretion from white adipocytes by insulin, glycolytic substrates, and amino acids. Am. J. Physiol. Endocrinol. Metab. 289, E166-E171.

Chenu, C., Serre, C. M., Raynal, C., BurtPichat, B., and Delmas, P. D. (1998). Glutamate receptors are expressed by bone cells and are involved in bone resorption. Bone 22, 295-299.

Chiu, J., DeSalle, R., Lam, H. M., Meisel, L., and Coruzzi, G. (1999). Molecular evolution of glutamate receptors: a primitive signaling mechanism that existed before plants and animals diverged. Mol. Biol. Evol. 16, 826-838.

Choi, K. Y., Chang, K., Pickel, J. M., Badger, J. D., and Roche, K. W. (2011). Expression of the metabotropic glutamate receptor 5 (mGluR5) induces melanoma in transgenic mice. Proc. Natl. Acad. Sci. U.S.A. 108, 15219-15224.

Davenport, R. (2002). Glutamate receptors in plants. Ann. Bot. 90, 549-557.

de Groot, J., and Sontheimer, H. (2011). Glutamate and the biology of gliomas. Glia 59, 1181-1189.

Dingledine, R., Borges, K., Bowie, D., and Traynelis, S. F. (1999). The glutamate receptor ion channels. Pharmacol. Rev. 51, 7-61.

continues to accumulate, and disruptions in glutamatergic mechanisms may contribute to a variety of bone diseases. However, owing to their apparent fundamental importance in numerous organ systems, future in vivo studies will require targeted manipulation of glutamatergic signaling to evaluate such consequences on bone homeostasis. Bone may be especially susceptible to glutamate interference as bone cells express the necessary receptors and transporters to transmit and receive glutamate signals for their normal functions. Glutamate transport appears critical for feedback control between $\mathrm{Oc}$ and $\mathrm{Ob}$ and disruption of this process may be relevant in osteoporosis. In osteoarthritis, glutamate receptor expression is altered compared to normal bone cells, and extracellular glutamate concentrations are significantly increased in affected joints in RA and could impact inflammatory responses. In arthritis, glutamate-sensitive nociceptors may be stimulated by this locally elevated signal, and may contribute to arthritis pain. Cancers growing in bone significantly disrupts bone metabolism and causes severe pain. As cancer cells are known to secrete glutamate, this errant extracellular signal may deregulate the tightly coupled glutamatergic bone remodeling process and may directly stimulate nociceptors. Pharmacologic modulation of the transporter secreting glutamate from cancer cells is offered as a potential strategy to reduce both metabolic disruption and pain in bone cancer, and in a wider context, suggests that the glutamatergic communication system holds significant potential as a therapeutic target in a number of bone-related disorders. As glutamate signaling is such a fundamental biological process, identifying how it functions in normal bone is vital to advancing our capacity to develop glutamate-based treatments for bone diseases.

\section{ACKNOWLEDGMENTS}

This work was supported in part by operating grants (to Gurmit Singh) provided by the Canadian Institutes for Health Research.

Doxsee, D. W., Gout, P. W., Kurita, T., Lo, M., Buckley, A. R., Wang, Y., Xue, H., Karp, C. M., Cutz, J. C., Cunha, G. R., and Wang, Y. Z. (2007) Sulfasalazine-induced cystine starvation: potential use for prostate cancer therapy. Prostate 67, 162-171.

Ducy, P., Amling, M., Takeda, S., Priemel, M., Schilling, A. F., Beil, F. T., Shen, J., Vinson, C., Rueger, J. M., and Karsenty, G. (2000). Leptin inhibits bone formation through a hypothalamic relay: a central control of bone mass. Cell 100, 197-207.

Elefteriou, F. (2008). Regulation of bone remodeling by the central and peripheral nervous system. Arch. Biochem. Biophys. 473, 231-236.

Elefteriou, F., Takeda, S., Liu, X., Armstrong, D., and Karsenty, G. (2003). Monosodium glutamatesensitive hypothalamic neurons contribute to the control of bone mass. Endocrinology 144, 3842-3847.

Enz, R. (2007). The trick of the tail: protein-protein interactions of metabotropic glutamate receptors. Bioessays 29, 60-73.

Flood, S., Parri, R., Williams, A., Duance, V., and Mason, D. (2007). Modulation of interleukin-6 and matrix metalloproteinase 2 expression in human fibroblast-like synoviocytes by functional ionotropic glutamate receptors. Arthritis Rheum. 56, 2523-2534.

Genever, P. G., and Skerry, T. M. (2001). Regulation of spontaneous glutamate release activity in osteoblastic cells and its role in differentiation and survival: evidence for intrinsic glutamatergic signaling in bone. FASEB J. 15, 1586-1588.

Genever, P. G., Wilkinson, D. J., Patton, A. J., Peet, N. M., Hong, Y., Mathur, A., Erusalimsky, J. D., and Skerry, T. M. (1999). Expression of a functional N-methyl-D-aspartatetype glutamate receptor by bone marrow megakaryocytes. Blood 93, 2876-2883. 
Gu, X., Zhang, J., Ma, Z., Wang, J., Zhou, X., Jin, Y., Xia, X., Gao, Q., and Mei, F. (2010). The role of N-methyl-Daspartate receptor subunit NR2B in spinal cord in cancer pain. Eur. J. Pain 14, 496-502.

$\mathrm{Gu}, \mathrm{Y} .$, and Publicover, S. J. (2000). Expression of functional metabotropic glutamate receptors in primary cultured rat osteoblasts. Cross-talk with N-methyl-Daspartate receptors. J. Biol. Chem. $275,34252-34259$

Hajati, A. K., Alstergren, P., Näsström, K., Bratt, J., and Kopp, S. (2009). Endogenous glutamate in association with inflammatory and hormonal factors modulates bone tissue resorption of the temporomandibular joint in patients with early rheumatoid arthritis. J. Oral Maxillofac. Surg. 67, 1895-1903.

Hajati, A. K., Näsström, K., Alstergren, P., Bratt, J., and Kopp, S. (2010). Temporomandibular joint bone tissue resorption in patients with early rheumatoid arthritis can be predicted by joint crepitus and plasma glutamate level. Mediators Inflamm. 2010, 627803 .

Hayashi, M., Morimoto, R., Yamamoto, A., and Moriyama, Y. (2003). Expression and localization of vesicular glutamate transporters in pancreatic islets, upper gastrointestinal tract, and testis. J. Histochem. Cytochem. 51, 1375-1390.

Hinoi, E., Fujimori, S., Nakamura, Y., and Yoneda, Y. (2001). Group III metabotropic glutamate receptors in rat cultured calvarial osteoblasts. Biochem. Biophys. Res. Commun. 281, 341-346.

Hinoi, E., Fujimori, S., Takemori, A., Kurabayashi, H., Nakamura, Y., and Yoneda, Y. (2002). Demonstration of expression of mRNA for particular AMPA and kainate receptor subunits in immature and mature cultured rat calvarial osteoblasts. Brain Res. 943 , 112-116.

Hinoi, E., Fujimori, S., and Yoneda, Y. (2003). Modulation of cellular differentiation by N-methyl-Daspartate receptors in osteoblasts. FASEB J. 17, 1532-1534.

Hinoi, E., Ohashi, R., Miyata, S., Kato, Y., Iemata, M., Hojo, H., Takarada, T., and Yoneda, Y. (2005a). Excitatory amino acid transporters expressed by synovial fibroblasts in rats with collagen-induced arthritis. Biochem. Pharmacol. 70, 1744-1755.

Hinoi, E., Wang, L., Takemori, A., and Yoneda, Y. (2005b). Functional expression of particular isoforms of excitatory amino acid transporters by rodent cartilage. Biochem. Pharmacol. 70, 70-81.

Hinoi, E., Takarada, T., Ueshima, T., Tsuchihashi, Y., and Yoneda, Y. (2004a). Glutamate signaling in peripheral tissues. Eur. J. Biochem. 271, 1-13.

Hinoi, E., Takarada, T., and Yoneda, Y. (2004b). Glutamate signaling system in bone. J. Pharmacol. Sci. 94, 215-220.

Hinoi, E., Takarada, T., Uno, K., Inoue, M., Murafuji, Y., and Yoneda, Y. (2007). Glutamate suppresses osteoclastogenesis through the cystine/glutamate antiporter. Am. J. Pathol. 170, 1277-1290.

Huggett, J. F., Mustafa, A., O’Neal, L., and Mason, D. J. (2002). The glutamate transporter GLAST-1 (EAAT1) is expressed in the plasma membrane of osteocytes and is responsive to extracellular glutamate concentration. Biochem. Soc. Trans. 30 $\mathrm{Pt}$ 6), 890-893.

Iemata, M., Takarada, T., Hinoi, E., Taniura, H., and Yoneda, Y. (2007). Suppression by glutamate of proliferative activity through glutathione depletion mediated by the cystine/glutamate antiporter in mesenchymal C3H10T1/2 stem cells. J. Cell. Physiol. 213, 721-729.

Itzstein, C., Cheynel, H., Burt-Pichat, B., Merle, B., Espinosa, L., Delmas, P. D., and Chenu, C. (2001). Molecular identification of NMDA glutamate receptors expressed in bone cells. J. Cell. Biochem. 82, 134-144.

Itzstein, C., Espinosa, L., Delmas, P. D., and Chenu, C. (2000). Specific antagonists of NMDA receptors prevent osteoclast sealing zone formation required for bone resorption. Biochem. Biophys. Res. Commun. 268, 201-209.

Kakegawa, W., Miyoshi, Y., Hamase, K., Matsuda, S., Matsuda, K., Kohda, K., Emi, K., Motohashi, J., Konno, R., Zaitsu, K., and Yuzaki, M. (2011). Dserine regulates cerebellar LTD and motor coordination through the $\delta 2$ glutamate receptor. Nat. Neurosci. 14, 603-611.

Kalariti, N., Lembessis, P., and Koutsilieris, M. (2004). Characterization of the glutamatergic system in MG-63 osteoblast-like osteosarcoma cells. Anticancer Res. 24, 3923-3929.

Kalariti, N., Lembessis, P., Papageorgiou, E., Pissimissis, N., and Koutsilieris, M. (2007). Regulation of the mGluR5, EAAT1 and GS expression by glucocorticoids in MG-63 osteoblast-like osteosarcoma cells. J. Musculoskelet. Neuronal Interact. 7, 113-118.
Kim, J. Y., Kanai, Y., Chairoungdua, A., Cha, S. H., Matsuo, H., Kim, D. K., Inatomi, J., Sawa, H., Ida, Y., and Endou, H. (2001). Human cystine/glutamate transporter: cDNA cloning and upregulation by oxidative stress in glioma cells. Biochim. Biophys. Acta 1512, 335-344.

Krnjevic, K. (2010). When and why amino acids? J. Physiol. (Lond.) 588(Pt 1), 33-44.

Lam, F. F., and Ng, E. S. (2010). Substance P and glutamate receptor antagonists improve the antiarthritic actions of dexamethasone in rats. Br. J. Pharmacol. 159, 958-969.

Lawand, N. B., Willis, W. D., and Westlund, K. N. (1997). Excitatory amino acid receptor involvement in peripheral nociceptive transmission in rats. Eur. J. Pharmacol. 324 169-177.

Liguz-Lecznar, M., and SkangielKramska, J. (2007). Vesicular glutamate transporters (VGLUTs): the three musketeers of glutamatergic system. Acta Neurobiol. Exp. (Wars) 67, 207-218.

Lin, T. H., Yang, R. S., Tang, C. H., Wu M. Y., and Fu, W. M. (2008). Regulation of the maturation of osteoblasts and osteoclastogenesis by glutamate. Eur. J. Pharmacol. 589, 37-44.

Lindblad, S. S., Mydel, P., Hellvard, A., Jonsson, I. M., and Bokarewa, M. I. (2012). The N-methyl-d-aspartic acid receptor antagonist memantine ameliorates and delays the development of arthritis by enhancing regulatory T cells. Neurosignals 20 61-71.

Lo, M., Wang, Y. Z., and Gout, P. W. (2008). The xc- cystine/glutamate antiporter: a potential target for therapy of cancer and other diseases. J. Cell. Physiol. 215, 593-602.

Marcaggi, P., Hirji, N., and Attwell, D. (2005). Release of L-aspartate by reversal of glutamate transporters. Neuropharmacology 49, 843-849.

Martin, T. J., and Seeman, E. (2008). Bone remodelling: its local regulation and the emergence of bone fragility. Best Pract. Res. Clin. Endocrinol. Metab. 22, 701-722.

Mason, D. J., and Huggett, J. F. (2002). Glutamate transporters in bone. J. Musculoskelet. Neuronal Interact. 2, 406-414.

Mason, D. J., Suva, L. J., Genever, P. G., Patton, A. J., Steuckle, S., Hillam, R. A., and Skerry, T. M. (1997) Mechanically regulated expression of a neural glutamate transporter in bone: a role for excitatory amino acids as osteotropic agents? Bone 20, 199-205.
McNearney, T., Baethge, B. A., Cao, S., Alam, R., Lisse, J. R., and Westlund, K. N. (2004). Excitatory amino acids, TNF- $\alpha$, and chemokine levels in synovial fluids of patients with active arthropathies. Clin. Exp. Immunol. $137,621-627$

McNearney, T., Speegle, D., Lawand, N., Lisse, J., and Westlund, K. N. (2000). Excitatory amino acid profiles of synovial fluid from patients with arthritis. J. Rheumatol. 27, 739-745.

Merle, B., Itzstein, C., Delmas, P. D., and Chenu, C. (2003). NMDA glutamate receptors are expressed by osteoclast precursors and involved in the regulation of osteoclastogenesis. J. Cell. Biochem. 90, 424-436.

Miyaji, T., Omote, H., and Moriyama, Y. (2010). A vesicular transporter that mediates aspartate and glutamate neurotransmission. Biol. Pharm. Bull. 33, 1783-1785.

Morimoto, R., Uehara, S., Yatsushiro, S. Juge, N., Hua, Z., Senoh, S., Echigo, N., Hayashi, M., Mizoguchi, T., Ninomiya, T., Udagawa, N., Omote, H., Yamamoto, A., Edwards, R. H., and Moriyama, Y. (2006). Secretion of L-glutamate from osteoclasts through transcytosis. EMBO J. 25, 4175-4186.

Narang, V. S., Pauletti, G. M., Gout, P. W., Buckley, D. J., and Buckley, A. R. (2003). Suppression of cystine uptake by sulfasalazine inhibits proliferation of human mammary carcinoma cells. Anticancer Res. 23 , 4571-4579.

Nedergaard, M., Takano, T., and Hansen, A. J. (2002). Beyond the role of glutamate as a neurotransmitter. Nat. Rev. Neurosci. 3, 748-755.

Niswender, C. M., and Conn, P. J. (2010). Metabotropic glutamate receptors: physiology, pharmacology, and disease. Annu. Rev. Pharmacol. Toxicol. 50, 295-322.

Olkku, A., Bodine, P. V., LinnalaKankkunen, A., and Mahonen, A. (2004). Glucocorticoids induce glutamine synthetase expression in human osteoblastic cells: a novel observation in bone. Bone 34 , 320-329.

Olkku, A., and Mahonen, A. (2008). Wnt and steroid pathways control glutamate signalling by regulating glutamine synthetase activity in osteoblastic cells. Bone 43, 483-493.

Olney, J. W. (1969). Brain lesions, obesity, and other disturbances in mice treated with monosodium glutamate. Science 164, 719-721.

Parisi, E., Almadén, Y., Ibarz, M., Panizo, S., Cardús, A., Rodriguez, M., Fernandez, E., and Valdivielso, J. M. (2009). N-methyl-D-aspartate 
receptors are expressed in rat parathyroid gland and regulate $\mathrm{PTH}$ secretion. Am. J. Physiol. Renal Physiol. 296, F1291-F1296.

Parisi, E., Bozic, M., Ibarz, M., Panizo, S., Valcheva, P., Coll, B., Fernández, E., and Valdivielso, J. M. (2010). Sustained activation of renal N-methyl$\mathrm{D}$-aspartate receptors decreases vitamin D synthesis: a possible role for glutamate on the onset of secondary HPT. Am. J. Physiol. Endocrinol. Metab. 299, E825-E831.

Patton, A. J., Genever, P. G., Birch, M. A., Suva, L. J., and Skerry, T. M. (1998). Expression of an N-methylD-aspartate-type receptor by human and rat osteoblasts and osteoclasts suggests a novel glutamate signaling pathway in bone. Bone 22, 645-649.

Peet, N. M., Grabowski, P. S., LaketicLjubojevic, I., and Skerry, T. M. (1999). The glutamate receptor antagonist MK801 modulates bone resorption in vitro by a mechanism predominantly involving osteoclast differentiation. FASEB J. 13, 2179-2185.

Piepoli, T., Mennuni, L., Zerbi, S., Lanza, M., Rovati, L. C., and Caselli, G. (2009). Glutamate signaling in chondrocytes and the potential involvement of NMDA receptors in cell proliferation and inflammatory gene expression. Osteoarthr. Cartil. 17, 1076-1083.

Ramage, L., Martel, M. A., Hardingham, G. E., and Salter, D. M. (2008). NMDA receptor expression and activity in osteoarthritic human articular chondrocytes. Osteoarthr. Cartil. 16, 1576-1584.

Ren, B. X., Gu, X. P., Zheng, Y. G., Liu, C. L., Wang, D., Sun, Y. E., and Ma, Z. L. (2012). Intrathecal injection of metabotropic glutamate receptor subtype 3 and 5 agonist/antagonist attenuates bone cancer pain by inhibition of spinal astrocyte activation in a mouse model. Anesthesiology $116,122-132$.

Rzeski, W., Turski, L., and Ikonomidou, C. (2001). Glutamate antagonists limit tumor growth. Proc. Natl. Acad. Sci. U.S.A. 98, 6372-6377.

Seidlitz, E. P., Sharma, M. K., Saikali, Z., Ghert, M., and Singh, G. (2009). Cancer cell lines release glutamate into the extracellular environment. Clin. Exp. Metastasis 26, 781-787.
Seidlitz, E. P., Sharma, M. K., and Singh, G. (2010a). A by-product of glutathione production in cancer cells may cause disruption in bone metabolic processes. Can. J. Physiol. Pharmacol. 88, 197-203.

Seidlitz, E. P., Sharma, M. K., and Singh, G. (2010b). Extracellular glutamate alters mature osteoclast and osteoblast functions. Can. J. Physiol. Pharmacol. 88, 929-936.

Sharma, M. K., Seidlitz, E. P., and Singh, G. (2010). Cancer cells release glutamate via the cystine/glutamate antiporter. Biochem. Biophys. Res. Commun. 391, 91-95.

Shigeri, Y., Seal, R. P., and Shimamoto, K. (2004). Molecular pharmacology of glutamate transporters, EAATs and VGLUTs. Brain Res. Brain Res. Rev. 45, 250-265.

Skerry, T. M. (2008). The role of glutamate in the regulation of bone mass and architecture. J. Musculoskelet. Neuronal Interact. 8, 166-173.

Skerry, T. M., and Genever, P. G. (2001). Glutamate signalling in nonneuronal tissues. Trends Pharmacol. Sci. 22, 174-181.

Sluka, K. A., Jordan, H. H., and Westlund, K. N. (1994). Reduction in joint swelling and hyperalgesia following post-treatment with a nonNMDA glutamate receptor antagonist. Pain 59, 95-100.

Spencer, G. J., Hitchcock, I. S., and Genever, P. G. (2004). Emerging neuroskeletal signalling pathways: a review. FEBS Lett. 559, 6-12.

Spencer, G. J., McGrath, C. J., and Genever, P. G. (2007). Current perspectives on NMDA-type glutamate signalling in bone. Int. J. Biochem. Cell Biol. 39, 1089-1104.

Stepulak, A., Luksch, H., Gebhardt, C., Uckermann, O., Marzahn, J., Sifringer, M., Rzeski, W., Staufner, C., Brocke, K. S., Turski, L., and Ikonomidou, C. (2009). Expression of glutamate receptor subunits in human cancers. Histochem. Cell Biol. 132, 435-445.

Suematsu, A., Tajiri, Y., Nakashima, T., Taka, J., Ochi, S., Oda, H., Nakamura, K., Tanaka, S., and Takayanagi, H. (2007). Scientific basis for the efficacy of combined use of antirheumatic drugs against bone destruction in rheumatoid arthritis. Mod. Rheumatol. 17, 17-23.
Szczesniak, A. M., Gilbert, R. W. Mukhida, M., and Anderson, G. I. (2005). Mechanical loading modulates glutamate receptor subunit expression in bone. Bone 37 63-73.

Takarada, T., Hinoi, E., Fujimori, S., Tsuchihashi, Y., Ueshima, T., Taniura, H., and Yoneda, Y. (2004). Accumulation of $[3 \mathrm{H}]$ glutamate in cultured rat calvarial osteoblasts. Biochem. Pharmacol. 68 177-184.

Takarada-Iemata, M., Takarada, T. Nakamura, Y., Nakatani, E., Hori, O. and Yoneda, Y. (2011). Glutamate preferentially suppresses osteoblastogenesis than adipogenesis through the cystine/glutamate antiporter in mesenchymal stem cells. J. Cell. Physiol. 226, 652-665.

Takeda, S., Elefteriou, F., Levasseur, R. Liu, X., Zhao, L., Parker, K. L., Armstrong, D., Ducy, P., and Karsenty, G. (2002). Leptin regulates bone formation via the sympathetic nervous system. Cell 111, 305-317.

Tanahashi, S., Ueda, Y., Nakajima, A., Yamamura, S., Nagase, H., and Okada, M. (2012). Novel $\delta 1$ receptor agonist KNT-127 increases the release of dopamine and Lglutamate in the striatum, nucleus accumbens and median pre-frontal cortex. Neuropharmacology 62, 2057-2067.

Taylor, A. F. (2002). Functional osteoblastic ionotropic glutamate receptors are a prerequisite for bone formation. J. Musculoskelet. Neuronal Interact. 2, 415-422.

Tremolizzo, L., DiFrancesco, J. C. Rodriguez-Menendez, V., Sirtori, E., Longoni, M., Cassetti, A., Bossi, M., El Mestikawy, S., Cavaletti, G., and Ferrarese, C. (2006). Human platelets express the synaptic markers VGLUT1 and 2 and release glutamate following aggregation. Neurosci. Lett. 404, 262-265.

Tzingounis, A. V., and Wadiche, J. I. (2007). Glutamate transporters: confining runaway excitation by shaping synaptic transmission. Nat. Rev. Neurosci. 8, 935-947.

Uno, K., Takarada, T., Nakamura, Y. Fujita, H., Hinoi, E., and Yoneda, Y. (2011). A negative correlation between expression profiles of runt-related transcription factor2 and cystine/glutamate antiporter xCT subunit in ovariectomized mouse bone. J. Pharmacol. Sci. 115, 309-319.

Waddell, T. G., and Miller, T. J. (1991) Chemical evolution of the citric acid cycle: sunlight photolysis of the amino acids glutamate and aspartate. Orig. Life Evol. Biosph. 21, 219-223.

Wang, L., Hinoi, E., Takemori, A., Nakamichi, N., and Yoneda, Y. (2006). Glutamate inhibits chondral mineralization through apoptotic cell death mediated by retrograde operation of the cystine/glutamate antiporter. J. Biol. Chem. 281, 24553-24565.

Watkins, J. C., and Jane, D. E. (2006). The glutamate story. Br. J. Pharmacol. 147(Suppl. 1), S100-S108.

Yamaki, M., Nakamura, H., Takahashi, N., Udagawa, N., and Ozawa, H. (2005). Transcytosis of calcium from bone by osteoclast-like cells evidenced by direct visualization of calcium in cells. Arch. Biochem. Biophys. 440, 10-17.

Young, V. R., and Ajami, A. M. (2001). Glutamine: the emperor or his clothes? J. Nutr. 131(Suppl. 9), 2449S-2459S.

Conflict of Interest Statement: The authors declare that the research was conducted in the absence of any commercial or financial relationships that could be construed as a potential conflict of interest.

Received: 15 April 2012; accepted: 30 June 2012; published online: 19 July 2012.

Citation: Cowan RW, Seidlitz EP and Singh $G$ (2012) Glutamate signaling in healthy and diseased bone. Front. Endocrin. 3:89. doi: 10.3389/fendo.2012.00089

This article was submitted to Frontiers in Bone Research, a specialty of Frontiers in Endocrinology.

Copyright (c) 2012 Cowan, Seidlitz and Singh. This is an open-access article distributed under the terms of the Creative Commons Attribution License, which permits use, distribution and reproduction in other forums, provided the original authors and source are credited and subject to any copyright notices concerning any third-party graphics etc. 